\title{
Acute myeloid leukaemia presenting as acute liver failure-a case report and literature review
}

\author{
Kai Sun ${ }^{1}$, Ryan J Reynolds ${ }^{1}$, Tiffany G Sheu ${ }^{2}$, Jessica A Tomsula ${ }^{2}$, Lara Colton ${ }^{1,3}$ and Lawrence Rice ${ }^{1,3}$ \\ ${ }^{1}$ Department of Medicine, Houston Methodist Hospital, Houston, TX 77030, USA \\ ${ }^{2}$ Department of Pathology and Genomic Medicine, Houston Methodist Hospital, Houston, TX 77030, USA \\ ${ }^{3}$ Weill Cornell Medical College, Houston, TX 77030, USA
}

\begin{abstract}
A 75-year-old woman presented with rapidly progressive fatigue, abdominal pain and jaundice. Physical examination revealed tender abdomen and splenomegaly. Magnetic resonance cholangiogram showed marked hepatomegaly, splenomegaly and scattered nodules or masses in the liver and spleen. The patient expired from multiorgan failure. Autopsy revealed infiltration of the liver, spleen and bone marrow by acute myeloid leukaemia.
\end{abstract}

Keywords: acute myeloid leukaemia, acute liver failure, obstructive jaundice

\section{Introduction}

In patients presenting with acute liver failure (ALF), acute myeloblastic leukaemia (AML) is extraordinarily rare and is associated with very high mortality. We cared for a patient who presented with acute hepatic failure and was diagnosed with AML on autopsy (albeit suspected immediately pre-mortem). We review the literature to gain insights into this problem and how outcomes might be improved.

\section{Case presentation}

A 75-year-old woman presented to another hospital with fatigue, right upper quadrant abdominal pain and jaundice, was evolving over several days. She denied fever, sick contacts, recent infectious symptoms, recent travel or new medications. Past medical history was remarkable only for moderate Parkinson's disease. Medications were aspirin, calcium-vitamin D3 and rasagiline. She was afebrile and jaundiced. Haemoglobin was $8.9 \mathrm{~g} / \mathrm{dL}$; white blood cells $6.35 \mathrm{k} / \mathrm{uL}$ with $63 \%$ neutrophils, $21 \%$ lymphocytes and $13 \%$ monocytes; platelets $30 \mathrm{k} / \mathrm{uL}$; alkaline phosphatase $92 \mathrm{U} / \mathrm{L}$; aspartate aminotransferase (AST) $62 \mathrm{U} / \mathrm{L}$; alanine aminotransferase (ALT) $104 \mathrm{U} / \mathrm{L}$ and total bilirubin 4.5 with $2.4 \mathrm{mg} / \mathrm{dL}$ direct fraction. Tests for Epstein-Barr virus, cytomegalovirus, hepatitis and

Correspondence to: Lawrence Rice Email: LRICE@houstonmethodist.org

ecancer $2019,13: 960$

https://doi.org/10.3332/ecancer.2019.960

Published: 09/09/2019

Received: 26/06/2019

Copyright: (c) the authors; licensee ecancermedicalscience. This is an Open Access article distributed under the terms of the Creative Commons Attribution License (http:// creativecommons.org/licenses/by/3.0), which permits unrestricted use, distribution, and reproduction in any medium, provided the original work is properly cited. 
human immunodeficiency viruses were negative. Autoimmune workup was negative, including anti-nuclear antibodies, anti-mitochondrial antibody, anti-Smith antibody and liver-kidney microsomal antibody. Magnetic resonance cholangiogram showed marked hepatomegaly, moderate splenomegaly and nodular areas of decreased T2-weighted signal within the liver and spleen parenchyma. She clinically deteriorated over a few days.

On transfer to Houston Methodist Hospital, she appeared acutely ill and moderately confused. The abdomen was distended, tense and tender in the right upper quadrant; the spleen was palpably enlarged. The white blood cell count remained $6.29 \mathrm{k} / \mathrm{uL}$ with $75 \%$ neutrophils, $18 \%$ lymphocytes and $5 \%$ monocytes; haemoglobin $7.9 \mathrm{~g} / \mathrm{dL}$; platelets $9 \mathrm{k} / \mathrm{uL}$; alkaline phosphatase $92 \mathrm{U} / \mathrm{L}$, AST $34 \mathrm{U} / \mathrm{L}$ and ALT $79 \mathrm{U} / \mathrm{L}$; total bilirubin $16.4 \mathrm{mg} / \mathrm{dL}$; direct bilirubin more than $10 \mathrm{mg} / \mathrm{dL}$; lactate dehydrogenase $(\mathrm{LDH}) 123 \mathrm{U} / \mathrm{L}$ and prothrombin time $21.2 \mathrm{~s}$, internationalised ratio 1.8, partial thromboplastin time 36, D-dimer 3.41 and fibrinogen $159 \mathrm{mg} / \mathrm{dL}$. Florid encephalopathy rapidly ensued, as AST increased to 1,669 , ALT to 518 , total bilirubin to 19.8 , along with acute renal failure, worsening coagulopathy and severe metabolic acidosis. A haematology consultant noted rare large blast cells on the peripheral smear ( 3 of 200 cells, Figure 1); peripheral blood flow cytometry did not detect these. The patient expired within few days of initial presentation before planned liver and bone marrow biopsies could be performed.

A limited autopsy of the liver, spleen and bone marrow revealed gross hepatosplenomegaly with diffusely mottled hepatic parenchyma and variably soft and firm red-black nodular spleen. Microscopic examination of the liver and spleen found effacement of the normal architecture by a diffuse neoplastic infiltrate (Figure 2). Residual hepatocytes were necrotic. The neoplastic cells had scant cytoplasm, immature nuclear chromatin and moderate nuclear pleomorphism. Bone marrow (Figure 3) was hypercellular (80\%) with expansion by neoplastic cells. While few residual erythroid and megakaryocytic elements were identifiable, there were no maturing myeloid precursors. Immunohistochemical stains confirmed the myeloid lineage of the neoplastic cells (strong positive myeloperoxidase) which also expressed monocytic (lysozyme) and erythroid (E-cadherin) markers. Subclassification of the AML was limited by cellular degeneration, so the process was classified as acute myeloid leukaemia, not otherwise specified.

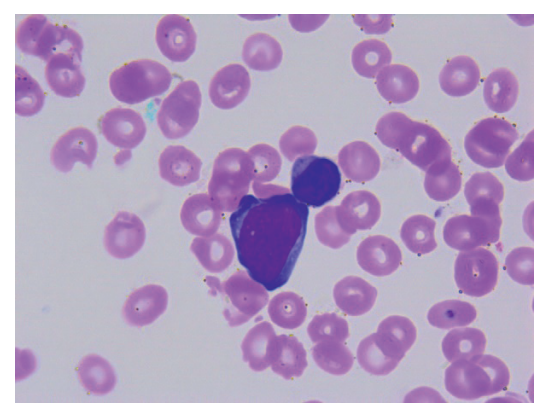

Figure 1. Peripheral smear.

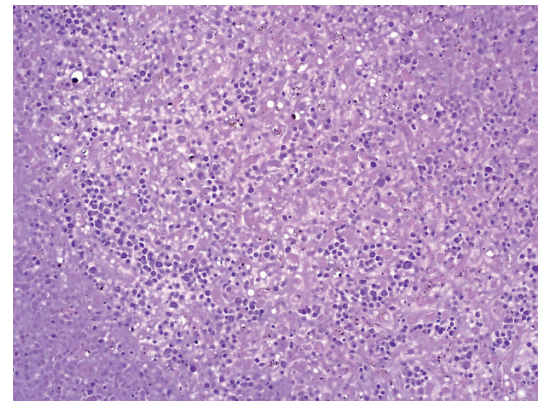

Figure 2. Microscopic examination of the liver. 


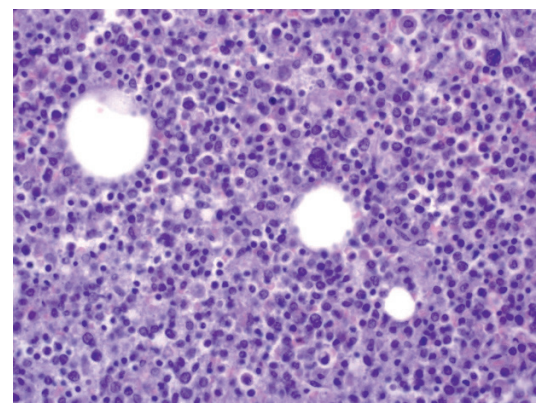

Figure 3. Microscopic examination of bone marrow.

\section{Discussion}

ALF is a life-threatening disease with high mortality rate [1]. The most common causes of ALF are drugs (acetaminophen is most common [2]) and viral infections [3]. Neoplastic infiltration as a cause of ALF is rare. In a large single centre study performed by Rowbotham et al. [4], only 18 out of 4,020 patients (0.44\%) had their ALF attributable to neoplastic infiltration. Rich et al. [5] found only 27 of 1,910 such cases (1.4\%). The most common malignancies in those studies were lymphoma (41\%-79\%) and metastatic breast cancer (30\%), whereas only two patients had ALF from acute leukaemia. AML as a cause of ALF is reported far less commonly than acute lymphoblastic leukaemia (ALL) in children [6-8] and in adults [9-13] but has been described in several case reports.

The first report of ALF due to AML was by Buchler and Cline [14] who described a young female with initially vaginal lymphoma; no details of the AML were provided in the case report. Seven subsequent cases of AML presenting as obstructive jaundice or ALF without distinguishable obstructive masses have been reported [12, 15-20] (see Table 1). All patients had abnormal blood counts that were reflected as anaemia and/ or thrombocytopenia and/or leukocytosis. Blasts were seen on peripheral smears in five of seven patients. Five of seven patients had liver and/or spleen enlargement detected on physical examination, abdominal imaging or autopsy.

In those cases, the ALF was manifest as cholestatic, hepatocellular or a mixed pattern, but hepatic sinusoidal infiltration was universally seen on liver biopsies. The patients who presented with very high bilirubin also had hepatocyte necrosis. We suspect that the liver damage first starts with hepatic sinusoidal infiltration causing ischaemia, then progresses to liver failure when the damage leads to liver tissue necrosis. Several cases [21-23] have described granulocytic sarcoma as the cause of obstructive jaundice which could be another mechanism of ALF in acute myeloid leukaemia. Even though our patient had mass-like lesions on imaging, the histologic examination revealed a diffuse involvement of the hepatic and splenic tissue.

The diagnosis of ALF due to AML is generally made by liver biopsy or by autopsy. While AML can present without circulating blasts, blasts on peripheral smear would typically point to the diagnosis of AML. In our case, none of the laboratory blood counts reported the presence of blasts, and even when rare peripheral blasts were noted by a haematology consultant, these were not detected by flow cytometry. Nevertheless, even if the diagnosis could have been made in a more timely fashion, this condition still engenders very high mortality. In the two previously mentioned case studies [4, 5], mortality rate was $100 \%$. In case reports, only two out of eight patients survived after chemotherapy. 


\begin{tabular}{|c|c|c|c|c|c|c|c|c|}
\hline 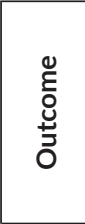 & 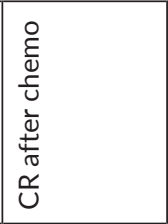 & 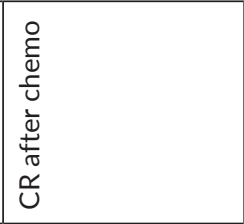 & \begin{tabular}{|l} 
売 \\
هั
\end{tabular} & \begin{tabular}{|l} 
売 \\
هั
\end{tabular} & 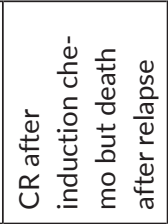 & 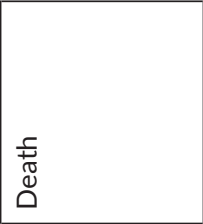 & 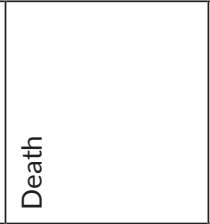 & 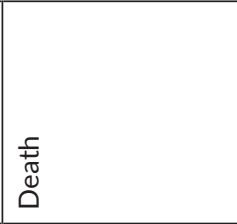 \\
\hline 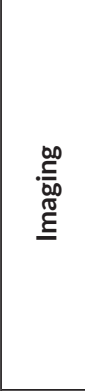 & 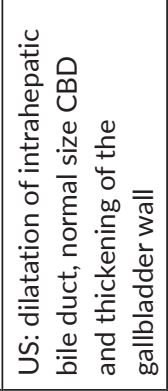 & 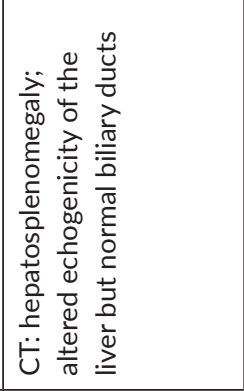 & 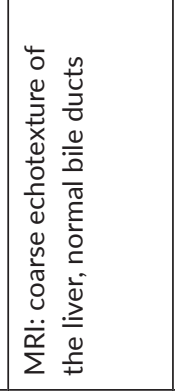 & 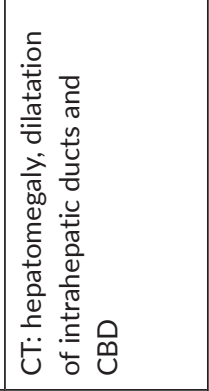 & 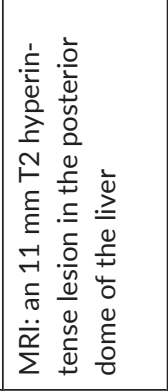 & 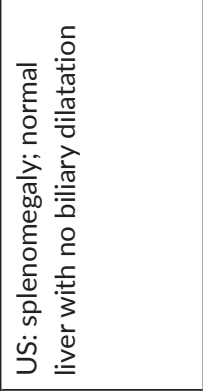 & 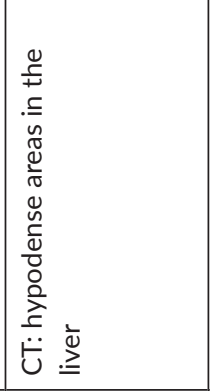 & 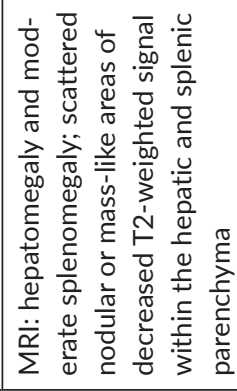 \\
\hline 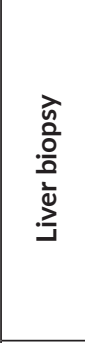 & 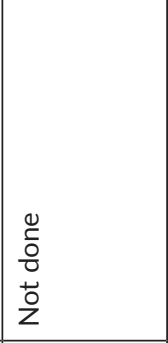 & 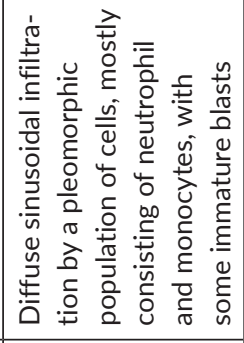 & 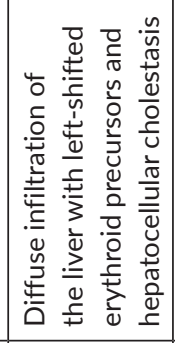 & 1 & 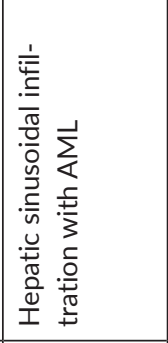 & 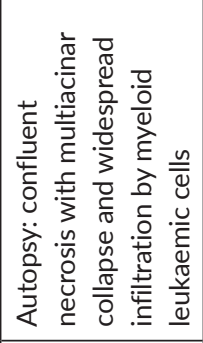 & 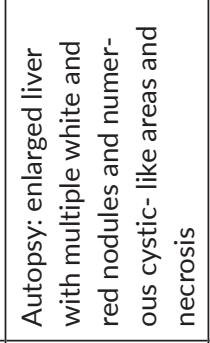 & 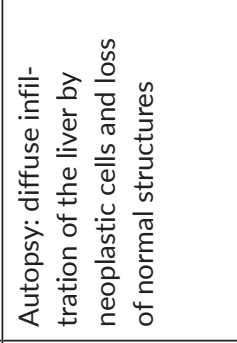 \\
\hline 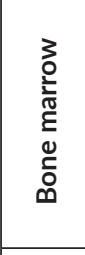 & $\sum_{<}$ & 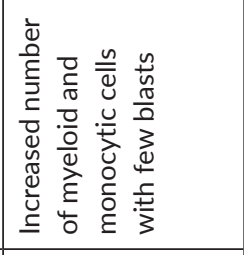 & \begin{tabular}{l}
$\stackrel{0}{\tilde{J}}$ \\
\multirow{2}{0}{} \\
\end{tabular} & 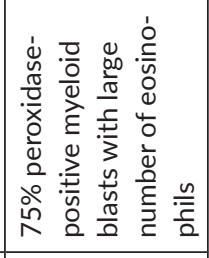 & 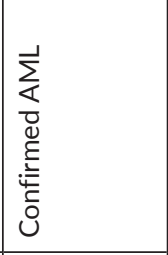 & 1 & 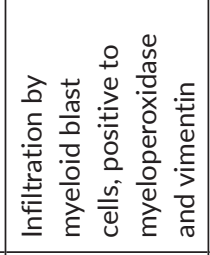 & 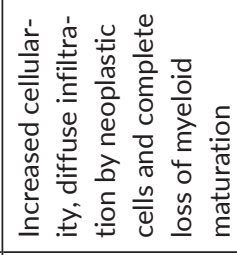 \\
\hline 离 & 1 & 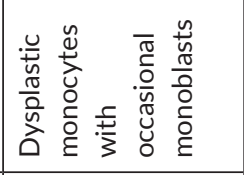 & 1 & \begin{tabular}{|l}
$\frac{n}{0}$ \\
$\frac{\omega}{0}$ \\
$\infty$
\end{tabular} & 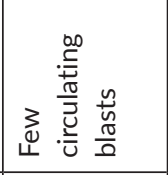 & 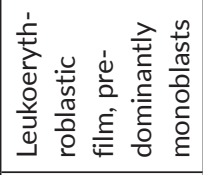 & 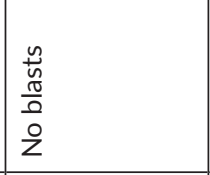 & \begin{tabular}{|l}
$\frac{n}{0}$ \\
$\frac{0}{0}$ \\
$\frac{\pi}{0}$ \\
$\frac{\pi}{\pi}$ \\
$\propto$ \\
\end{tabular} \\
\hline 章 & 1 & 1 & 1 & 1 & & $\begin{array}{l}n \\
\infty \\
\infty \\
\infty \\
\text { in }\end{array}$ & $\begin{array}{l}\hat{n} \\
m \\
m \\
m\end{array}$ & \\
\hline . & 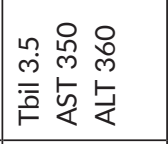 & 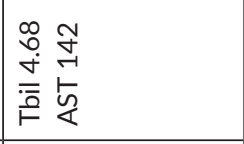 & 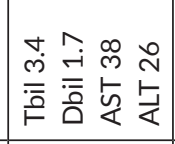 & 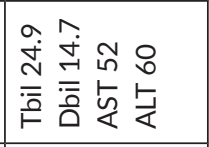 & 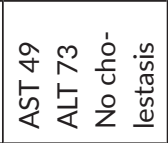 & 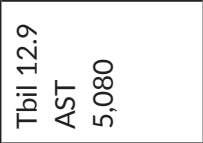 & 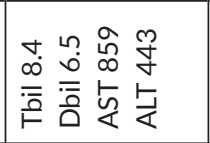 & 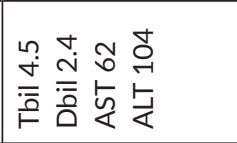 \\
\hline Ü & 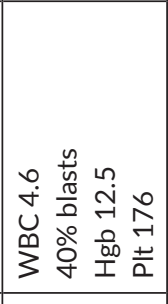 & 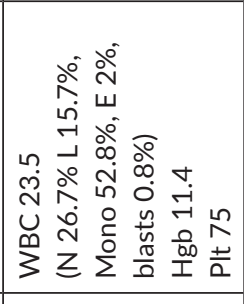 & 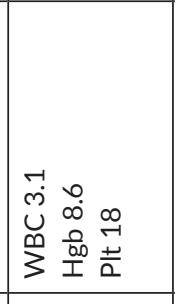 & 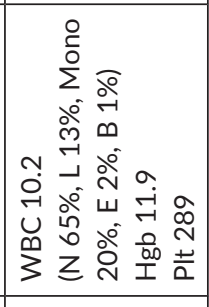 & 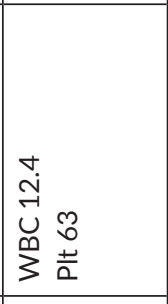 & 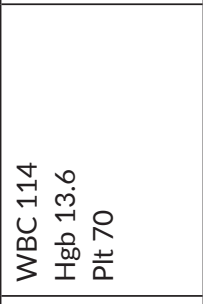 & 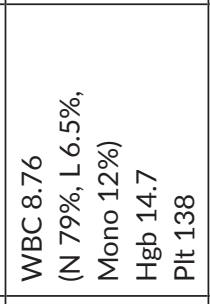 & 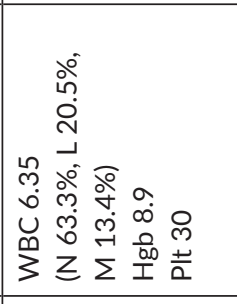 \\
\hline 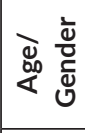 & 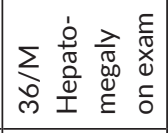 & $\begin{array}{l}\sum \\
\text { O } \\
\end{array}$ & $\begin{array}{l}4 \\
\text { 岁 } \\
0\end{array}$ & 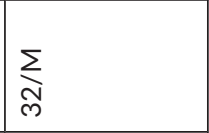 & $\begin{array}{l}4 \\
0 \\
0\end{array}$ & 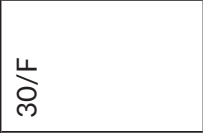 & 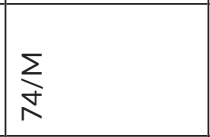 & $\underset{⿱ N}{\stackrel{L}{N}}$ \\
\hline 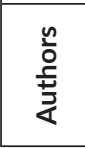 & 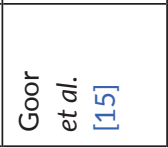 & 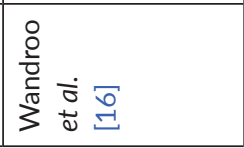 & 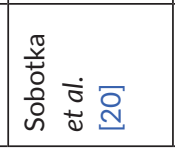 & 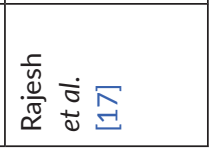 & 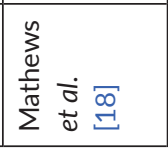 & 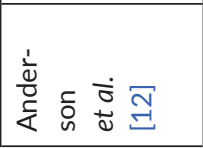 & 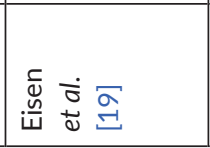 & $\begin{array}{l}0 \\
0 \\
0 \\
\vdots \\
\vdots \\
0\end{array}$ \\
\hline
\end{tabular}

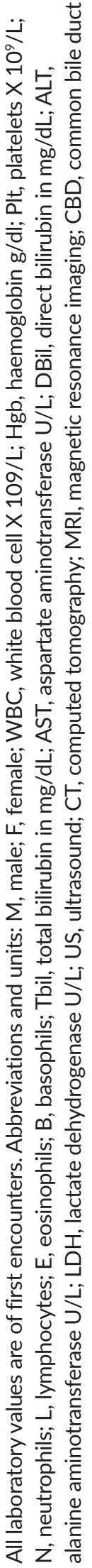




\section{Conclusion}

Even though AML as a cause of obstructive jaundice or ALF is rare, it should be considered as differential if patients have abnormal complete blood count (CBC) and hepatic or splenic enlargement. Peripheral smears should be done first in a timely manner if abnormal CBC is present. If unexplained abnormalities are present on peripheral smears in the setting of abnormal $\mathrm{CBC}$ and hepatomegaly or splenomegaly, bone marrow or liver biopsy should not be delayed to rapidly establish a diagnosis and timely initiate chemotherapy which would afford the patient some reasonable chance of remission and survival.

\section{Funding}

No funding was received for this case report.

\section{Conflicts of interest}

The authors declare that they have no conflicts of interest.

\section{Acknowledgments}

The authors would like to express their very great appreciation to pathologists Dr Ekene Okoye, Dr Tara Miller and Dr Arthur Zieske at Houston Methodist Pathology and Genomic department for their valuable assistance in gathering information on autopsy and the presentation of the case.

\section{References}

1. Grek A and Arasi L (2016) Acute liver failure AACN Adv Crit Care 27(4) 420-429 https://doi.org/10.4037/aacnacc2016324 PMID: 27959298

2. Castaldo ET and Chari RS (2006) Liver transplantation for acute hepatic failure HPB 8(1) 29-34 https://doi. org/10.1080/13651820500465741

3. Schiødt FV, Davern TJ, and Shakil AO, et al (2003) Viral hepatitis-related acute liver failure Am J Gastroenterol 98(2) 448-453 https://doi. org/10.1016/S0002-9270(02)05891-4 PMID: 12591067

4. Rowbotham D, Wendon J, and Williams R (1998) Acute liver failure secondary to hepatic infiltration: a single centre experience of 18 cases Gut 42(4) 576-580 https://doi.org/10.1136/gut.42.4.576 PMID: 9616324 PMCID: 1727084

5. Rich NE, Sanders C, and Hughes RS, et al (2015) Malignant infiltration of the liver presenting as acute liver failure Clin Gastroenterol Hepatol Off Clin Pract J Am Gastroenterol Assoc 13(5) 1025-1028

6. Rivet C, Leverger G, and Jacquemin E, et al (2014) Acute leukemia presenting as acute hepatitis without liver failure J Pediatr Gastroenterol Nutr 59(5) 640-641 https://doi.org/10.1097/MPG.0000000000000484 PMID: 25003374

7. Litten JB, Rodríguez MM, and Maniaci V (2006) Acute lymphoblastic leukemia presenting in fulminant hepatic failure Pediatr Blood Cancer 47(6) 842-845 https://doi.org/10.1002/pbc.20544

8. Kader A, Vara R, and Egberongbe Y, et al (2004) Leukaemia presenting with fulminant hepatic failure in a child Eur J Pediatr 163(10) 628-629 PMID: 15290266

9. Powell N, Rusli F, and Hubscher SG, et al (2006) Adult T-cell leukemia presenting with acute liver failure Leuk Res 30(10) 1315-1317 https://doi.org/10.1016/j.leukres.2005.12.026 PMID: 16516291 
10. McElreath DP, Angtuaco TL, and Staggs B, et al (2006) T cell prolymphocytic leukemia: a rare cause of acute liver failure Dig Dis Sci 51(4) 819-821 https://doi.org/10.1007/s10620-006-3213-0 PMID: 16615010

11. Suso A, Sola A, and Osay L, et al (2014) Acute lymphatic leukemia presenting in fatal fulminant hepatitis Medicina (Mex) 74(2) 178-179

12. Anderson SH, Richardson P, and Wendon J, et al (2001) Acute liver failure as the initial manifestation of acute leukaemia Liver 21(4) 287-292 https://doi.org/10.1034/j.1600-0676.2001.021004287.x PMID: 11454193

13. Dellon ES, Morris SR, and Tang W, et al (2006) Acute liver failure due to natural killer-like T-cell leukemia/lymphoma: a case report and review of the literature World J Gastroenterol 12(25) 4089-4092 https://doi.org/10.3748/wjg.v12.i25.4089 PMID: 16810767 PMCID: 4087729

14. Buchler DA and Kline JC (1972) Primary lymphoma of the vagina Obstet Gynecol 40(2) 235-237 PMID: 4558652

15. Goor Y, Goor O, and Michalewitcz R, et al (2002) Acute myeloid leukemia presenting as obstructive jaundice J Clin Gastroenterol 34(4) 485-486 https://doi.org/10.1097/00004836-200204000-00023 PMID: 11907369

16. Wandroo FA, Murray J, and Mutimer D, et al (2004) Acute myeloid leukaemia presenting as cholestatic hepatitis J Clin Pathol 57(5) 544-545 https://doi.org/10.1136/jcp.2003.013565 PMID: 15113866 PMCID: 1770297

17. Rajesh G, Sadasivan S, and Hiran KR, et al (2006) Acute myeloid leukemia presenting as obstructive jaundice Indian J Gastroenterol Off J Indian Soc Gastroenterol 25(2) 93-94

18. Mathews E, Laurie T, and O'Riordan K, et al (2008) Liver involvement with acute myeloid leukemia Case Rep Gastroenterol 2(1) 121-124 https://doi.org/10.1159/000120756 PMID: 21490850 PMCID: 3075178

19. Eisen A, Dovrish Z, and Hadari R, et al (2008) Jaundice and acute liver failure as the first manifestation of acute myeloid leukemia Isr Med Assoc J IMAJ 10(10) 733-735 PMID: 19009957

20. Sobotka LA, Malli A, and Chen W, et al (2018) Acute liver failure due to liver parenchymal infiltration with acute myelogenous leukaemia in a patient with myelodysplastic syndrome BMJ Case Rep https://doi.org/10.1136/bcr-2018-224590 PMID: 29954762

21. Lillicrap DP, Ginsburg AD, and Corbett WE (1982) Relapse of acute myelogenous leukemia presenting with extrahepatic obstruction of the biliary tract Can Med Assoc J 127(10) 1000-1001 PMID: 6958346 PMCID: 1862281

22. Mano Y, Yokoyama K, and Chen C-K, et al (2004) Acute myeloid leukemia presenting with obstructive jaundice and granulocytic sarcoma of the common bile duct Rinsho Ketsueki 45(9) 1039-1043 PMID: 15510832

23. González-Vela MC, Val-Bernal JF, and Mayorga M, et al (2006) Myeloid sarcoma of the extrahepatic bile ducts presenting as obstructive jaundice APMIS Acta Pathol Microbiol Immunol Scand 114(9) 666-668 https://doi.org/10.1111/j.1600-0463.2006.apm_491.x 